\title{
Purification of hemolysin from Aspergillus fumigatus and study its cytotoxic effect on normal cell line (REF) in vitro
}

\author{
Batool Omran Theeb ${ }^{1}$, Farooq Ibrahem Mohammad ${ }^{2}$, Abdulkareem Jasim \\ Hashim $^{3}$ and Sumia Sami Hashim ${ }^{3}$ \\ 1- Department of Biology, Iraqia University \\ 2- Biotechnology Research Center, Al- Nahrain University \\ 3- Department of Biotechnology, College of science, Baghdad University. Baghdad-Iraq.
}

\begin{abstract}
Aspergillus fumigtus produced a protenaceous hemolysin, when incubated on sheeps blood agar, from 41 isolates thirty isolates $(73.1 \%)$ has able to produce hemolysin. Hemolysin purified from tryptic soy broth using ion exchang and gel filtaration and found to have amolecular weight of approximately $74.52 \mathrm{KD}$ a. In this study, hemolysin was used in an experimental model to study its Cytotoxic activity by evaluating effect on REF cell line (Rat embryonic fibroblast), on exposure time of 24 hrs at three different concentrations triplicate of each concentration were used, Cytotoxicity of the purified compounds are active against REF cell line under study and a toxic effect was clear with a significant difference at the level of probability $(\mathrm{p}<$ 0.05 ) and this effect was increase gradually with the increase of hemolysin concentration.
\end{abstract}

Keywords: Aspergillus fumigatus, Hemolysin, Cytotoxic activity.

\section{INTRODUCTION}

Aspergillus fumigatus, apathogenic mould causing a wide range of diseases including aspergillosis, produces a series of toxic substances which appear to act inan additive and/or synergic way on cells.

Hemolysin (Asp-HS). The protein is secreted into the environment and can kill cells that are in the vicinity of the spore. In IA patients this secrete can be found in the urine (Davies, 1991; Arruda et al., 1992a; Arruda et al., 1992b; Kurup et al., 1994; Lamy and; Latgé, 1999). The hemolysin, which enables the fungus to disrupt blood cells, contains negatively charged domains and can also be detected in infected patients. However, despite of the facts that the hemolysin has toxic effects it seems not to be a main virulence factor but a compound that increases the effects of other toxic factors involved in pathogenicity (Ebina et al., 1983; Yokota et al., 1985; Fukuchi et al., 1996; Malicev et al.,
2007). The hemolysin produced by $A$. fumigatus (asp-hemolysin) promotes Aspergillosis (Ebina et al., 1982), and may also promote opportunistic infections, (Young et al., 1970).

\section{MATERIALS AND METHODS}

Screening the ability of 41 A. fumigatus isolates for hemolysin production

Forty one of $A$. fumigatus isolates isolated from patients with aspergillosis from Chect and respiratory diseases specialized center, Ministry of health, Baghdad governorate these isolates grown on potato dextrose agar (PDA), One drop of spore suspension $5^{*} 10^{6} A$. fumigatus of each isolates was inoculated on sheep blood agar (SBA). The plates were incubated at $37{ }^{\circ} \mathrm{C}$ for 7 days, triplicate of each isolates. The evidence of hemolysin in the medium indicated by presence of clear hemolysis in the medium and considered as a positive result. Mean of hemolytic diameter were 
calculated in each plate (Donohue et al., 2006).

\section{Purification of Hemolysin}

Aspergillus fumigatus isolates give high hemolysis on SBA was grown on PDA and the conidia recovered, Approximately $1 * 10^{5}$ spores were added to $500 \mathrm{ml}$ of tryptic soy broth (TSB). The cultures were incubated at $23{ }^{\circ} \mathrm{C}$ for 48 $\mathrm{hr}$ on an incubator shaker at $100 \mathrm{rpm}$. Subsequently, the temperature was raised to $35^{\circ} \mathrm{C}$ and the incubation continued for an additional $72 \mathrm{hrs}$. The fungal mass was then removed by filtering through Whatman 541 filter paper in a Buchner funnel. The concentrate from the filtration was then subjected to ion exchange chromatography (Berne et al., 2005).

Ion exchange and Gel filtration chromatography

DEAE-Cellulose column $(2 \times 23 \mathrm{~cm})$ was prepared according to Whitaker and Bernard, (1972) and equilibrated with 20 $\mathrm{mM}$ Tris $\mathrm{HCl}$ (2.7) buffer $(0.05 \mathrm{M}$, pH8.0).

Fraction was plated on SBA and hemolysis noted at $24 \mathrm{hrs}$. Then these fractions pooled together for the last step of purification by gel filtration chromatography using sephadex G $50.5 \mathrm{ml}$ of the protein solution obtained from the elution fractions of ion exchange chromatograph was added gently to column surface and eluted using $0.1 \mathrm{M}$ potassium phosphate buffer $\mathrm{pH} 8.0$ with flow rate of $20 \mathrm{ml} /$ hour $(5 \mathrm{ml}$ for each fraction). Optical density (at 280nm), Fractions represents protein concentration were pooled and kept at $4^{\circ} \mathrm{C}$ for further experiments.

Determination the molecular weight of hemolysin using sodium Dodecyl Sulfate-Polyacrylamide gel electrophoresis(SDS- PAGE) The molecular weight of protease and hemolysin determined by analyzed the pictures of column in photocapt analysis software (Hassan, 2009).

\section{Subculture of REF cell line:}

Single cell suspension was prepared by treating $25 \mathrm{~cm}^{3}$ tissue culture flask with $2 \mathrm{ml}$ trypsin solution incubated for 2 $\min$ at $37^{\circ} \mathrm{C}$ in an incubator supplemented with $(5 \%) \quad \mathrm{CO}_{2}$ after detachment of the cells from the flask surface by gently tapping of the flask followed by the addition of $20 \mathrm{ml}$ of growth medium supplemented with $10 \%$ fetal bovine serum, then the viability test of the cells was made by using trypan blue dye which stains the dead cells. Cells suspension was well mixed followed by transferring $200 \mu \mathrm{l} /$ well to the 96 well flat bottom micro titer plate using automatic micropipette containing $\left(1 \times 10^{5}\right.$ cell/well). Plates were incubated at $37^{\circ} \mathrm{C}$ in an incubator supplemented with (5\%) $\mathrm{CO}_{2}$ until $60-70 \%$ confluence of the internal surface area of the well for REF cell line (Freshney, 2000).

\section{Cytotoxicity assay:}

To detect the growth inhibition of REF cell line, culture of this cell line was incubated with different concentrations of each compound used in our study these compounds done by different purification technique depend on the nature of the compound, cells were treated and incubated with the purified extract of hemolysin, three concentrations at triplicate form of each extract to investigate the cytotoxic effect of this extract respectively, the concentrations used as follows: hemolysin $(2.5,5,10 \mu \mathrm{g} / \mathrm{ml})$, triplicate form of each concentration were used. Negative Control was achieved by incubating REF cell line with only maintenance medium.

\section{Detection of the Cytotoxic Effect:}

Neutral red assay used to detect the cytotoxic effect. After elapsing the incubation period, $100 \mu \mathrm{l} /$ well of neutral red dye freshly prepared were added to each well then plates incubated for $2 \mathrm{hrs}$, viable cells will uptake the dye and the dead not, the plates washed by PBS to remove the excess dye, then $100 \mu 1 /$ well 
of eluent solution were added to each well to withdraw the dye from the viable cells. Optical density of each well was measured by using ELISA reader at 492nm wave length (Freshney, 2010; Mahony et al.,1989).

Percentage of the inhibitory rate was measured according to (Wang et al., 2003) as follows:

$$
\text { I.R. }=\frac{\text { O.D. of control - O.D. of test }}{\text { O.D. of control }} * 100
$$

\section{Statistical Analysis:}

The values of the investigated parameters were given in terms of mean \pm standard error, and differences between means were assessed by analysis of variance (ANOVA) and Duncan test, using SPSS computer program version 7.5. Differences in results were considered significant at probability value equal or less than 0.05 and 0.001(SAS, 2004).

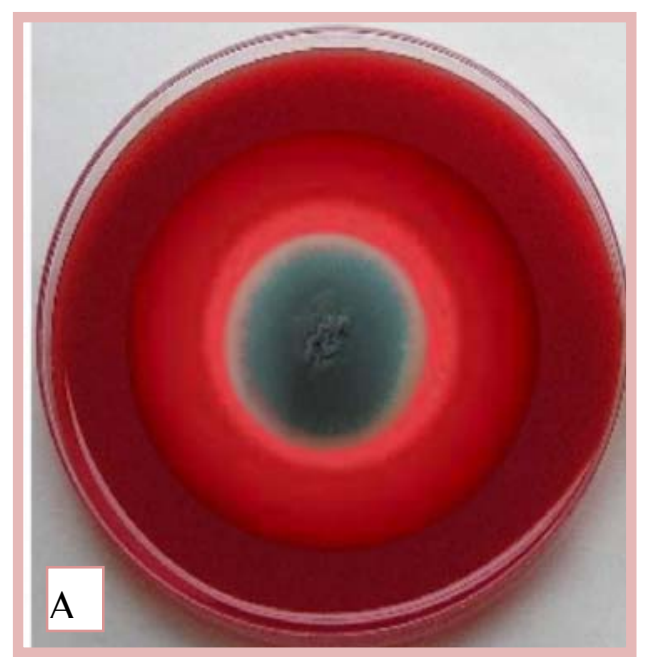

\section{RESULTS AND DISCUSSION Screening of $A$. fumigatus isolates for hemolysin production.}

In order to select the efficient isolate for hemolysin production, screening of $41 \mathrm{~A}$. fumigatus isolates screening was done using SBA . Thirteen isolates $(73.1 \%)$ from $41 \mathrm{~A}$. fumigatus has able to produce hemolysin on SBA medium as shown in fig. (1-A), and (26.9\%) from $41 \mathrm{~A}$. fumigatus isolates which have been unable to produce hemolysin on SBA as shown in fig. (1B). All the hemolysin production isolates of A. fumigatus included in this study give the clear zone but at different ratio.

Table (1) summarizes all information's obtained from calculate the hemolysis diameter of each isolate. Highly significant differences were shown $(\mathrm{P}<0.001)$ between the hemolysin producers isolates. Production of hemolysin on SBA medium ranged between $(1-8 \mathrm{mlm})$.

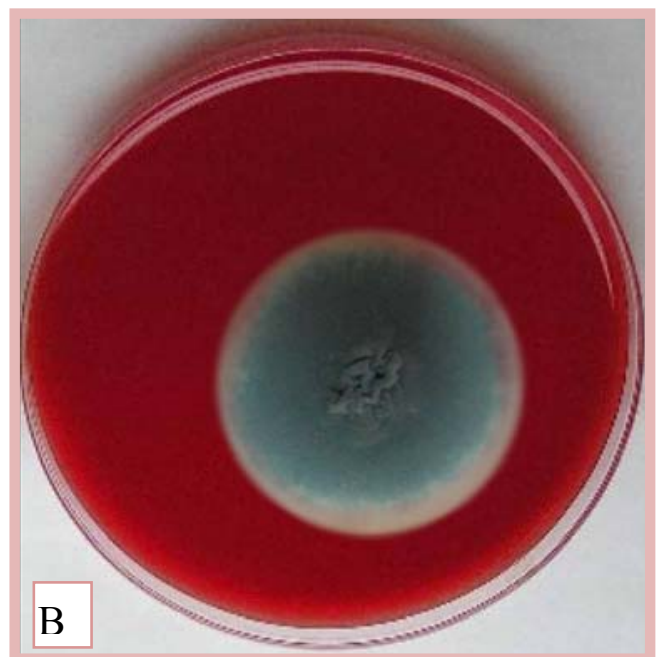

Fig. 1: Growth of Aspergillus fumigatus on sheep blood agar (SBA) 7 day, $37^{\circ} \mathrm{C}$. A: Aspergillus fumigatus produce hemolysin B: Aspergillus fumigatus non produce hemolysin .

Isolate AFUI regarded the efficient isolate in hemolysin production and purification by ion exchange and gel filtration chromatography to study affect of hemolysin in vitro and selected AFUI for pathological studies since it give highest production.

Hemolysin produced from the strain of A. fumigatus isolated from different sources pathogenic and environmental (Ebina et al., 1982). 
Table 1: Ability of Aspergillus fumigatus isolates in production hemolysinon sheep blood agar at $37 \mathrm{C}$ for 7 days.

\begin{tabular}{|c|c|c|}
\hline No. of isolate & Symbol of isolate & Hemolysin prodution \pm SE $\mathrm{mlm}$ \\
\hline 1 & AFU1 & $8.0 \pm 0.5$ \\
\hline 2 & AFU2 & 300 \\
\hline 3 & AFU3 & $\mathbf{0} \pm \mathbf{0}$ \\
\hline 4 & AFU4 & $4.0 \pm 1.1$ \\
\hline 5 & AFU5 & $6.0 \pm$ \\
\hline 6 & AFU6 & $2.0 \pm 0.5$ \\
\hline 7 & AFU7 & $2.0 \pm 0.5$ \\
\hline 8 & AFU8 & $4.0 \pm 1.7$ \\
\hline 9 & AFU9 & $3.6 \pm 1.2$ \\
\hline 10 & AFU10 & $\mathbf{0} \pm \mathbf{0}$ \\
\hline 11 & AFU11 & $\mathbf{0} \pm$ \\
\hline 12 & AFU12 & $3.0 \pm 1.0$ \\
\hline 13 & AFU13 & $2.0 \pm$ \\
\hline 14 & AFU14 & $\mathbf{0} \pm \mathbf{0}$ \\
\hline 15 & AFU15 & $7.0 \pm 0.5$ \\
\hline 16 & AFU16 & $\mathbf{0} \pm \mathbf{0}$ \\
\hline 17 & AFU17 & $0 \pm 0$ \\
\hline 18 & AFU18 & $2.0 \pm 0$ \\
\hline 19 & AFU19 & $2.0 \pm 0$ \\
\hline 20 & AFU20 & $0 \quad \pm$ \\
\hline 21 & AFU21 & $3.0 \pm 1.1$ \\
\hline 22 & AFU22 & $\mathbf{0} \quad \pm \mathbf{0}$ \\
\hline 23 & AFU23 & $7.0 \pm 1.1$ \\
\hline 24 & AFU24 & $\pm \quad 0$ \\
\hline 25 & AFU25 & $6.0 \pm$ \\
\hline 26 & AFU26 & $\mathbf{0} \pm \mathbf{0}$ \\
\hline 27 & AFU26 & $5.0 \pm 1.1$ \\
\hline 28 & AFU28 & $4.0 \pm$ \\
\hline 29 & AFU29 & $7.0 \pm \quad 1.1$ \\
\hline 30 & AFU30 & $3.0 \pm$ \\
\hline 31 & AFU31 & $2.0 \pm 0.5$ \\
\hline 32 & AFU32 & $5.0 \pm \quad 1.1$ \\
\hline 33 & AFU33 & $4.0 \pm 0.5$ \\
\hline 34 & AFU34 & $4.0 \pm$ \\
\hline 35 & AFU35 & $2.0 \pm$ \\
\hline 36 & AFU36 & $3.0 \pm 1.5$ \\
\hline 37 & AFU37 & $1.0 \pm$ \\
\hline 38 & AFU38 & $5.0 \pm 1.1$ \\
\hline 39 & AFU39 & $0 \pm 0$ \\
\hline 40 & AFU40 & $7.0 \pm 1.1$ \\
\hline 41 & AFU41 & $\mathbf{0}$ \\
\hline
\end{tabular}

significantly different. $\mathrm{p}<0.0001$ 


\section{Hemolysin purification}

Results of ion exchange chromatography point out that there was no peak of protein in washing step, while four peaks of protein were separated when eluted association proteins, with the appearance of high protein concentration in peaks from (56-81 fraction) as shown in fig. (2) Hemolysin of high protein concentration peaks in elution steps mean that the hemolysin from A. fumigatus had isoforms; in the word the protein purified from elution steps had a negative charge adverse to the ion exchanger, fractions which appeared hemolytic activity on SBA were selected for next step of purification gel filtration.

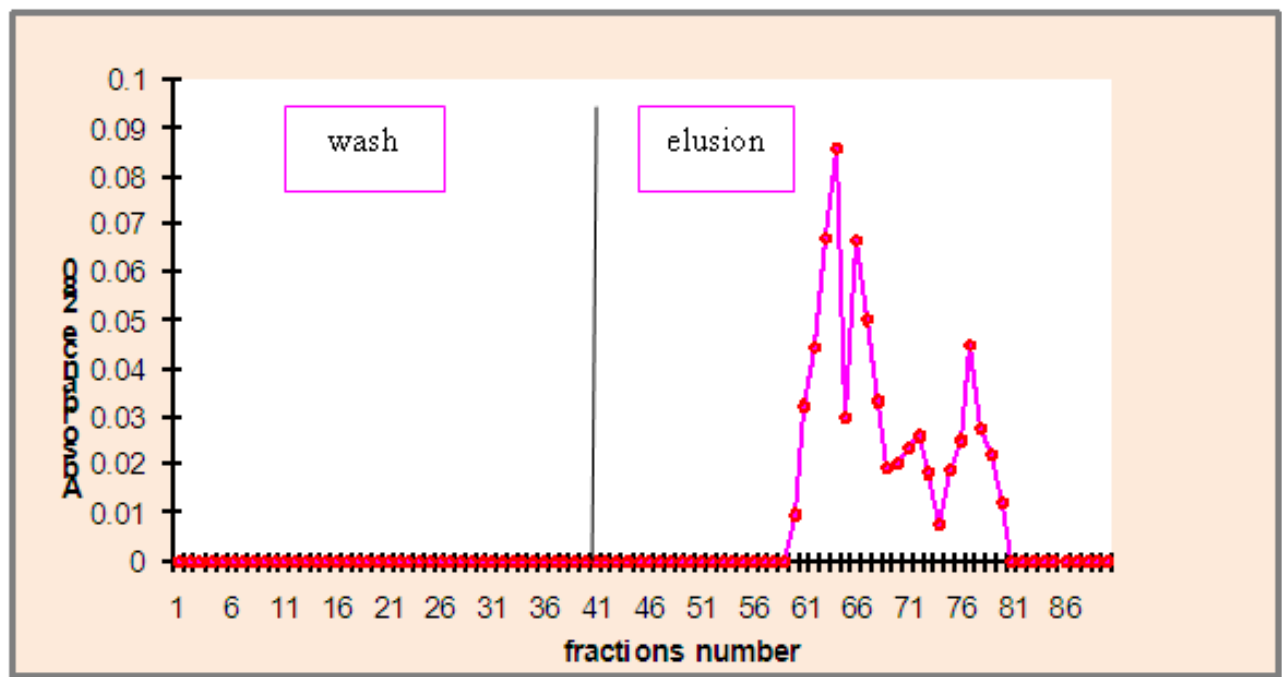

Fig. 2: Ion exchange chromatography for purification of hemolysin produced from Aspergillus.fumigatus using DEAE-Cellulose column $(2 \times 23 \mathrm{~cm})$ with a flow rate of 20 $\mathrm{ml} /$ hour.

Gel filtration chromatography technique was the next step used in the purification of hemolysin produced by $A$. fumigatus after purification by ion exchange chromatography technique. A volume of $5 \mathrm{ml}$ of partially purified hemolysin sparately was applied on Sephadex G-50 column $(1.6 \times 24 \mathrm{~cm})$ which previously equilibrated with 0.1 $\mathrm{M}$ potassium phosphate buffer ( $\mathrm{pH} 8.0$ ). Sephadex G-50 column which allows ability of separation with high degree of purification (Sivasankar, 2005). Protein was eluted thought the column matrix in a flow rate of $20 \mathrm{ml} /$ hour. Protein peaks were detected by measuring the optical density at $280 \mathrm{~nm}$ using UV-VIS spectrophotometer. Results in fig. (3) showed that only one peak (22-31) Fractions included in this peak were pooled, then protein concentration, were measured. Ten microliters of each fraction was plated on SBA and incubated at $37{ }^{\circ} \mathrm{C}$, and hemolysis noted as shown in fig. (4). After purification, hemolysin revealed a clear zone when place on SBA lyses the blood cells underneat Hemolysins lyses RBCs by creating pores or holes in red blood cell membranes resulting in the release of iron that promotes microbial growth (Bullen,1981) Hemolysins are critical virulence factors (Johnson et al., 1985; Ou Said et al., 1988). 


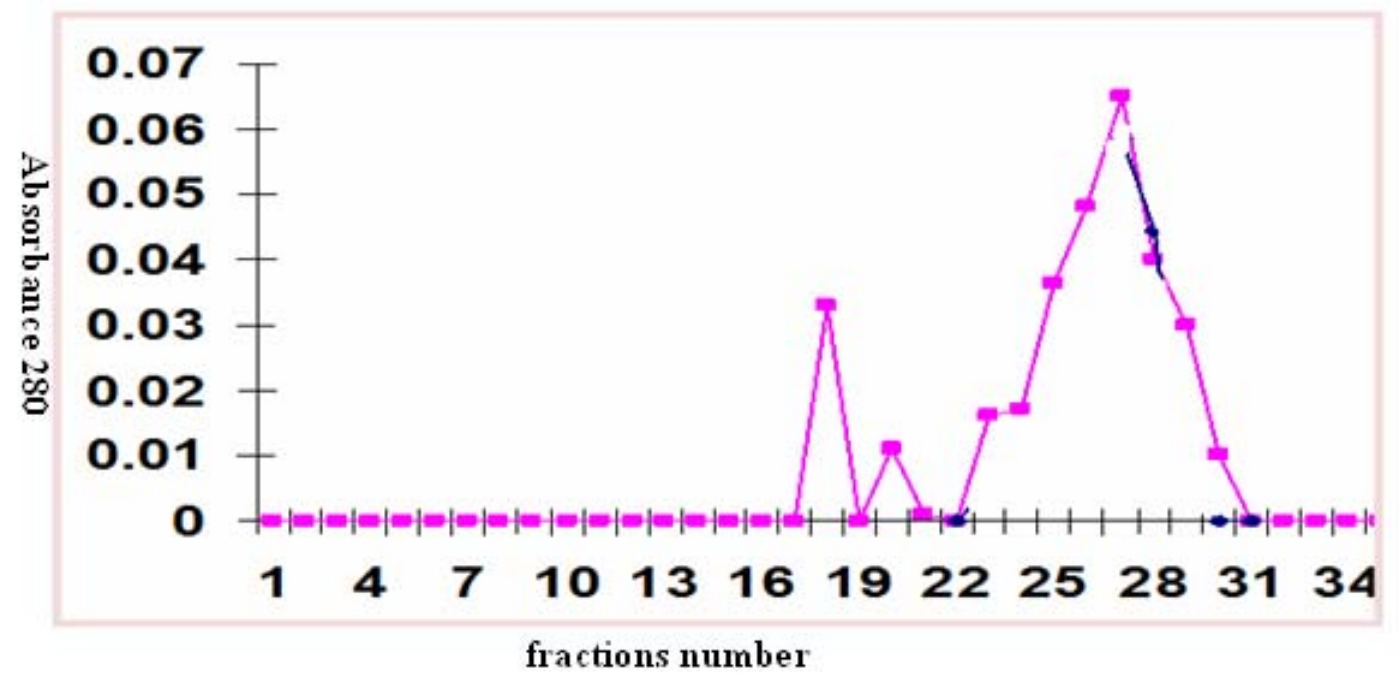

Fig. 3: Gel filtration chromatography for purification of hemolysin extracted from Aspergillus fumigatus using Sephadex G-50 column $(1.6 \times 24 \mathrm{~cm})$ equilibrated with potassium phosphate buffer $\mathrm{pH} 8.0$, fraction volume was $5 \mathrm{ml}$ at flow rate of $20 \mathrm{ml} /$ hour.

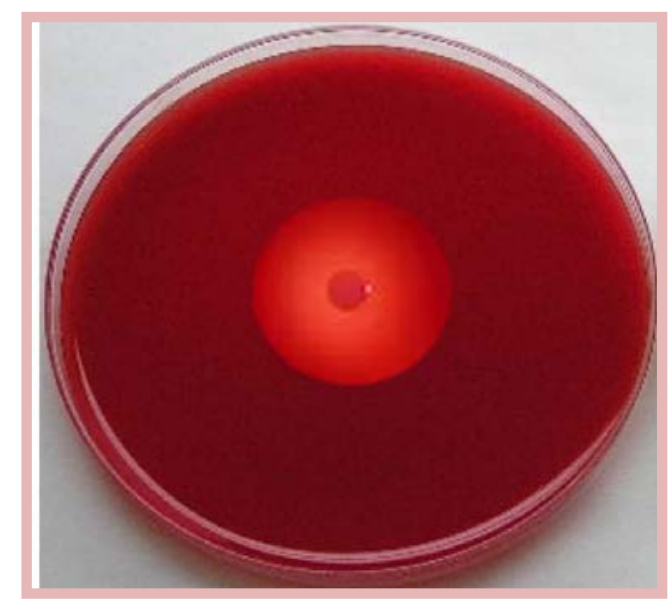

Fig. 4: ability of purified hemolysin fraction of hemolysis in sheep blood agar at $37{ }^{\circ} \mathrm{C}$ and $24 \mathrm{hrs}$.

\section{SDS-PAGE analysis}

Result in figure (5) and indicates analysis of hemolysin profile of $A$. fumigatus which appeared one band with molecular weight $74.52 \mathrm{KDa}$ agreement with Sonilr (2006) which determines the molecular weight of hemolysin purified from $A$. niger $72 \mathrm{KDa}$ Since hemolysin has an alpha helical structure, it may behave like the alpha helical bundle toxins and like in the molecular weight, e.g., diphtheria toxin (MW $75 \mathrm{kDa}$ ), colicins (MW $78 \mathrm{kDa}$ ), endotoxins (MW70-135 $\mathrm{kDa}$ ) and Pseudomonas aeruginosa exotoxin (MW $77 \mathrm{kDa}$ ) (Parker and Pattus, 1993).

\section{Cytotoxic Effect of Hemolysin on REF} Cell Line, in vitro

The cytotoxicity effect of purified hemolysin on normal cell line was studied by evaluating its effect on REF cell line (Rat embryonic fibroblast), passage 15 on exposure time of $24 \mathrm{hrs}$ at three different concentrations $(2.5,5$, $10 \mu \mathrm{g} / \mathrm{ml}$ ) triplicate of each concentration were used by Neutral Red assay. 


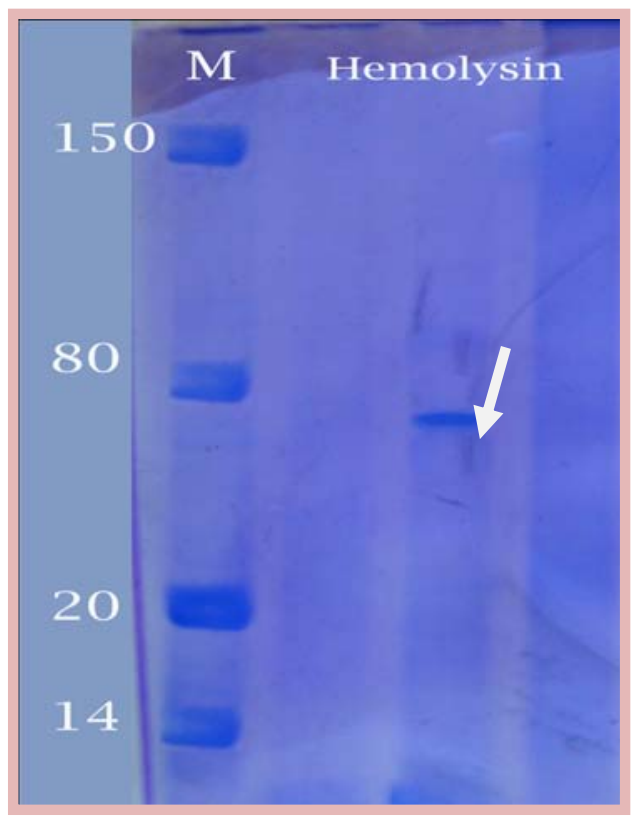

Fig. 5: Protein profile analysis of hemolysin purified from A. fumigatus by $10 \%$ SDS-PAGE, L1: Protein markers, L2: Pure hemolysin analysis

Cytotoxic Effect of Hemolysin.

Significant cytotoxic effect $(\mathrm{P} \leq$ 0.05 ) was observed on growth of REF cell line at the concentrations 2.5, 5, and $10 \mu \mathrm{g} / \mathrm{ml}$ with growth inhibition percentage $33.79 \%, 64.44 \%$ and 76.68
$\%$, respectively, as shown in the Fig. (6). There was increase in the inhibitory effect when compared with the control (the same cell line without any treatment).

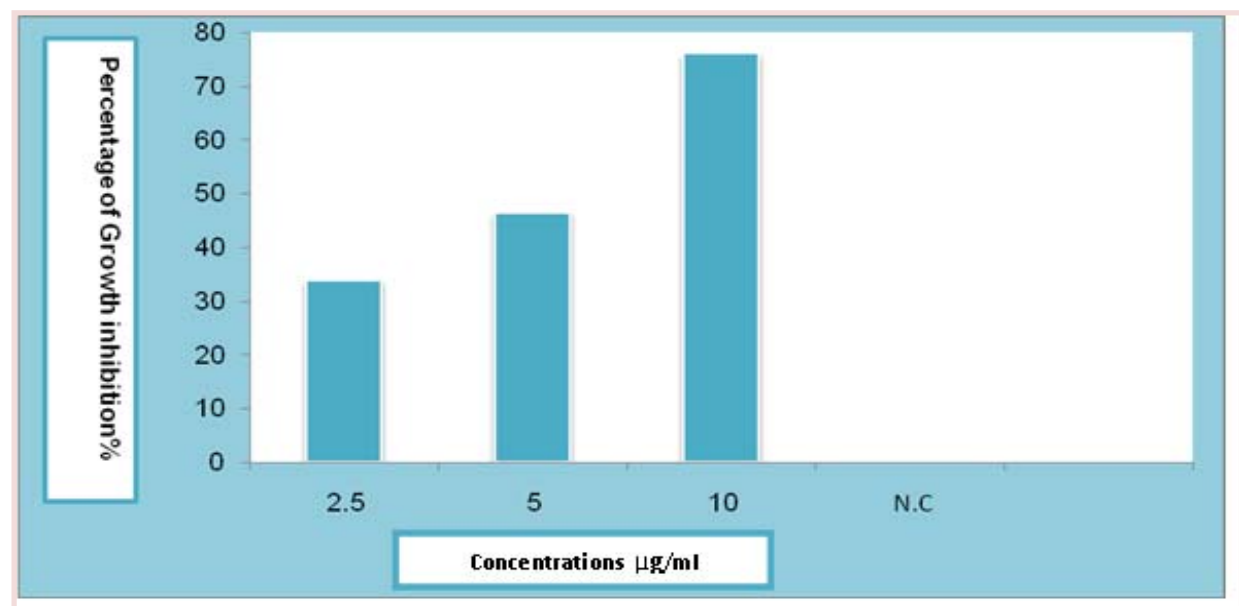

Fig. 6: Cytotoxicity effect of different concentrations of purified Hemolysin from A. fumigatus on REF cell line after $24 \mathrm{hr}$.

Hemolysin is cytolytic and hemolytic protein and can induce effective permeabilization in cell, these activities of hemolysin help us to explain the cytotoxic effect of hemolysin in our result. Hemolysin has an alpha helical structure, Alpha helical toxin cause damage in susceptible cells by creating pores in membranes. (Donohue et al., 2006) experiments showing specific interaction of hemolysin with plasma membrane domains, suggest hemolysin has a specific binding protein, the existence of phospholipid membrane domains involved in cell signaling, endocytosis and attachment of several 
toxins and protein indicate that these cells membrane domains probably serve as attachment sites for Hemolysin, leading to their aggregation and formation of the pore (Shepherd et al., 1980). Cytotoxicity of hemolysin may be due to the ability of hemolysin to induce DNA damage and mutations (which is considered to be an early event in the process of carcinogenesis) in cell cultures or in animals. It was indicating that the various hemolysin can induce genotoxicity of dietary carcinogens in vitro considering that the degree of induction was strongly species dependent (Ebina et al., 1982; Ebina et al.,1994; Berne et al., 2005).

\section{REFERENCES}

Arruda, L.K., Platts-Mills, T.A., Longbottom, J.L., el-Dahr, J.M., and Chapman, M.D. (1992b) Aspergillus fumigatus: identification of 16,18 , and $45 \mathrm{kd}$ antigens recognized by human $\operatorname{IgG}$ and $\operatorname{IgE}$ antibodies and murine monoclonal antibodies. J Allergy Clin Immunol 89: 1166-1176.

Arruda, L. K., Mann, B.J., and Chapman, M.D. (1992a) Selective expression of a major allergen and cytotoxin, AspfI, in Aspergillus fumigatus. Implications for the immunopathogenesis of Aspergillusrelated diseases. J Immunol 149: 3354-3359.

Berne, S.; Sepc `ic,' K . And Anderluh, G. (2005). Effect of $\mathrm{pH}$ on the pore forming activity and conformational stability of ostreolysin, alipid raftbinding protein from the edible mushroom Pleurotus ostreatus. Biochemistry; 44: 11137-11147.

Bullen, J.J. (1981). The significance of iron in infection. Rev. Infect. Dis. 3: 1127-1138.

Davis, R.H., (2000). Neurospora: Contributions of a Model Organism. Oxford, England: Oxford University Press.
Donohue, M.; Wei, W.; Wu, J.; Zawia, N. H.; Hud, N.; Jesus, V. D.; Schmechel, D.; and Vesper, S. (2006). Characterization of nigerlysin, hemolysin produced by Aspergillus niger, and effect on mouse neuronal cells in vitro. J. Toxicology 219:150-155.

Ebina K, Yokota K, Sakaguchi O. (1982). Studies on the toxin of Aspergillus fumigatus. XIV. Relationship between Asphemolysin. and experimental infection of mice. Jpn J Med Mycol; 23:246-252.

Ebina, K., Yokota, K., and Sakaguchi, O. (1983). Studies on toxin of Aspergillus fumigatus. XVI. Biological properties of Asphemolysin as a parasitic factor. Jpn J Med Mycol 24: 247-252.

Freshney R. I. (2000). "Culture of animal cells: A manual for basic technique" $4^{\text {th }}$ Ed. Wiley- Liss, A John wiley and Sons, Inc. Publication, New York.

Freshney, R.I. (2010). Culture of animal cells. $6^{\text {th }}$ Edition. Wiley- Liss. New York.

Fukuchi, Y., Kumagai, T., Ebina, K. and Yokota, K. (1996). Apolipoprotein $\mathrm{B}$ inhibits the hemolytic activity of asp-hemolysin from Aspergillus fumigatus. Biol Pharm Bull 19: 547 550.

Hassan, R. A. (2009). Evaluation Activity of S-layer Proteins and Filtrate of Lactobacillus spp. Against Some Pathogenic Microorganisms and as Antitumor Agent in vitro. M.Sc. thesis. College of Sciences, Al-Nahrain University.

Johnson, P., Lindberg, M., Haraldsson, I., and Waldstrom, T. (1985). Virulence of Staphylococcus aureus in a mouse mastitis model: studies of alpha hemolysin, coagulase and protein $\mathrm{A}$ as possible virulence determinants with protoplast fusion and gene cloning. Infect. Immun. 49: 765- 
769.

Kurup, V. P., Kumar, A., Kenealy, W. R. and Greenberger, P. A. (1994). Aspergillus ribotoxins react with $\mathrm{Ig}$ $\mathrm{E}$ and Ig $\mathrm{G}$ antibodies of patients with allergicbronchopulmonary aspergillosis. J. Lab. Clin. Med. 123: 749-756.

Laemmli, U. K. (1970). Cleavage of structural proteins during the assembly of the head of bacteriophage T4. Nature (London) 227:680-685.

Lamy, B. and Davies, J. (1991) solation and nucleotide sequence of the Aspergillus restrictus gene coding for the ribonucleic toxin restrictocin and its expression in A. nidulans: the leader sequence protects producing strains from suicide. I. Nucleic Acids Res. 19:1001-1006.

Mahony, D. E.; Gilliatt, E.; Dawson, S.; Stockdale, E. and Lee, H. S. (1989). Vero cell assay for rapid detection of Clostridium perfringins enterotoxin. Appl. Environ. Microbiol. J., 55:2141-2143.

Malic`ev,M.; Chowdhury,H.H.;Macek,P. and Sepcic,K.(2007) . Effect of ostreolysin, an Asp-hemolysin isoform, on human chondrocytes and osteoblasts, and possible role of Asp-hemolysin in pathogenesis. Medical Mycology.J., 45: 123-130.

OuSaid, A.M., Contrepois, M.G., Vartanian, M. D. and Girardeau, J.,
(1988). Virulence factors and markers in Escherichia coli from calves with bacteremia. Am. J. Vet. Res. 49, 1657-1660.

Parker, M.W., Pattus, F. (1993). Rendering a membrane protein soluble inwater: a common packing motif in bacterial protein toxins. TIBS 18: 391-395.

SAS users (2004). Guide personal computer (ver.7) inst. Inc. Cary. Nc. USA.

Shepherd, V.L., Vandre, D.D., Eltin, g.J.J., and Montgomery, R. (1980). Effects of cesalin on the ultrastructure and biological properties of cultured mammalian cells. Cancer Res. 40: 225-231.

Sivasankar, A. (2005). Bioseparation: Principle and Techniques. PrenticeHall of India, New delhi, ISBN- 81203-2649.

Wang, B.; Relling, M. V. and Storm, M. C. (2003). Evaluation of immunologic cross reaction of antiasparaginase antibodies in acute lymphoblastic leukemia (ALL) and lymphoma patients. Leukemia. J., 17:1583-1588.

Young, R.C., Bennett, J.E., Vogel, C.L., Carbone, P.P., DeVita, V.T., (1970). Aspergillosis: the spectrum of the disease in 98 patients. Medicine 49: 147-173. 